\author{
Military Technical College \\ Kobry El-Kobbah, \\ Cairo, Egypt.
}

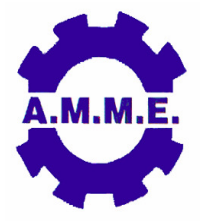

\title{
STRESS AND DYNAMIC ANALYSIS OF SIMPLE REMOTELY OPERATED UNDERWATER VEHICLE
}

\author{
A. M. Badawy* and A. A. Omer ${ }^{\star}$
}

\begin{abstract}
Stress and dynamic analyses of submerged structures, especially Remotely Operated Underwater Vehicles (ROV) are the first step to build and design an underwater vehicle. In the present paper the high pressure produced form the water column weight plus the dynamic pressure produced from the vehicle speed is calculated. The stress affects the structure due to both static and dynamic loads is obtained. The fulfillment of these analyses needed the use of finite element model simulating the structure. Stress analysis is made by the finite element package ABAQUS $^{\circledR}$ version 6.8. The dynamic analysis introduces the equation of motion representing the dynamic behavior of the vehicle under the effect of the hydrodynamic load against the vehicle motion. Equations define the added mass coefficients are used mathematically to estimate the added mass coefficients. The added mass coefficients are estimated practically by means of a free decay pendulum motion test. The hydrodynamic coefficients (linear and quadric damping coefficients,) are determined using the computational fluid dynamic through software ANSIS CFX. These coefficients are compared by the coefficients estimated practically by means of a free decay pendulum motion test. Good agreement between practical and CFD hydrodynamic coefficient is achieved. The variation of ROV acceleration and velocity with time is obtained for surge and heave directions with varying thrusting load.
\end{abstract}

\section{KEY WORDS}

Finite element method; Computational Fluid Dynamic; Hydrodynamic coefficient; added mass; surge; heave.

\footnotetext{
* Egyptian Armed Forces.
} 


\section{INTRODUCTION}

ROV's are one of the systems used to explore the underwater environment, the extreme underwater environment which needed to be explored and controlled obligate the designer to create a system capable of withstanding these conditions. The high pressure produced form the water column weight plus the dynamic pressure produced from the vehicle speed have to be considered. In order to simulate the motion of underwater vehicle as near to real as possible a good, accurate, and simple modeling should be presented.

Several authors [1-5] used two orthogonal coordinate systems to establish a dynamic model, one is a global coordinate system $(O, X, Y, Z)$ fixed at the ocean surface ship with origin at $O, Z$ axis pointing vertically down to the water, and the $X, Y$ axes being in two mutually perpendicular horizontal directions. The other is local coordinate system $(0, x, y, z)$ fixed on the vehicle with the origin at $0, x$ axis pointing to the nose of the vehicle, $z$ axis pointing to the belly of the vehicle and the $y$ axis completing the right-hand system with the other two axis

Thrusters are the source of the propulsion force moving the vehicle; also represent the force vector in the equation of motion, which decide the way the vehicle moves or respond. Thrusters also had great keenness from authors [1-5]; they consider the thruster force and moment as a constant value regardless the ambient flow. But Jinhyun K., Wan K. C. [6] studied the effect of ambient flow on the thruster.

Total mass matrix of the remotely operated vehicle was presented by ZHU Ke-qiang et. al. [5] who said that all vehicles have a longitudinal symmetric plane $\mathrm{xoz}\left(\mathrm{y}_{\mathrm{G}}=0\right)$, the added mass coefficients $A_{i j}$ with $(i+j)$ odd are all zeros. The total mass matrix $[\mathrm{M}]$ consisting of inertia and added mass terms.

Modeling of the coupled motion of the structure and the fluid also is of great effect on the motion study and on stress analysis. François A. and Jose A. [7], explained all the issues concerning fluid structure interaction problems (coupled motion, drag force, added mass, hydrodynamic coefficients ...etc).

Stress and dynamic analyses of submerged structures, especially Remotely Operated Underwater Vehicles (ROV) are the first step to build and design an underwater vehicle.. The design procedure of the underwater vehicles goes through the logic steps of shape selection, calculating the stress that affect the structure due to both static and dynamic loads, and then the dynamic analysis which introduce the equations of motion representing the dynamic behavior of the vehicle under the effect of the hydrodynamic load against the vehicle motion. The fulfillment of these analyses needed the use of finite element model simulating the structure.

In the present paper, the stress analysis is made by the finite element package ABAQUS $^{\circledR}$ version 6.8. Equations define the added mass coefficients are used mathematically to estimate the added mass coefficients. The added mass coefficients are estimated practically by means of a free decay pendulum motion test. The free decay pendulum motion test is used also to determine the linear and quadric damping coefficients which are compared with the linear and quadric 
damping coefficient estimated by a Computational Fluid dynamic Model using ANSYS CFX ${ }^{\circledR}$.

It is found that the use of free decay pendulum motion test gives sufficient results for hydrodynamic coefficients, the open frame ROV could be created with low strength materials, since the load is equally distributed over all surfaces preventing the buckling hazard. Good agreement between hydrodynamic coefficients obtained using free decay pendulum motion and the computational fluid dynamics CFX.

\section{STRUCTURE DESIGN}

The ROV structure mainly made to support the instrumentations and other systems installed on the ROV frame, and keep it safe. It is essential in the field of underwater vehicle design to select the suitable frame, holding the sensors, driving, and control instruments. ROV structure could be open or closed frame according to the operation environment.

\section{Shape and Material Selection}

The materials have a great contribution on the structure process, underwater conditions obligates the designer to use materials with high corrosion resistance also with high strength to withstand the high pressure especially for high depth ROV's. Aluminum titanium alloys are widely used in ROV's programs; they have high strength and high corrosion resistance, also with light weight to reduce the inertia force produced from the vehicle's acceleration [8]. During this study a PVC open shell frame is used as shown in Fig. (1). PVC is used for its low weight, low price, and ease of assembly.

\section{ROV Frame Characteristics}

The frame selected is $38^{*} 38^{*} 18 \mathrm{~cm}$ parallelogram shape made from one inch PVC tubes. The tubes are pasted using a special paste to prevent any slippage during operation. The tubes are including different holes to permit the water to inter the tubes which insure more stability to the vehicle. The ROV frame used is made of PVC with a density of $1323 \mathrm{~kg} / \mathrm{m}^{3}$, total in air weight of $2.557 \mathrm{Kg}$, while the holes causes the additional water weight of $1.182 \mathrm{~kg}$, this gives a total ROV weight of $3.739 \mathrm{~kg}$. The center of gravity of the frame is located in the middle of the frame due to the similarity of the frame around the three axes. While the same frame has buoyancy force of $2.24 \mathrm{~kg}$ force due to volume of the frame submerged in the water of density $1000 \mathrm{~kg} / \mathrm{m}^{3}$. As shown from the values above the total weight is higher than the buoyancy force, which means negative buoyancy of the frame.

\section{Thruster Layout Configuration}

The layout of the thrusters on the frame are controlled by the number of degrees of freedom needed to the vehicle, also the thrusters' layout might be useful in fault accommodation in case of thruster fault. In the present case study the motion needed to be achieved is translation in surge $(\mathrm{x})$, and heave $(\mathrm{z})$, and rotation about (y) yaw motion. For this type of motion 3 thrusters is installed in the location shown in 


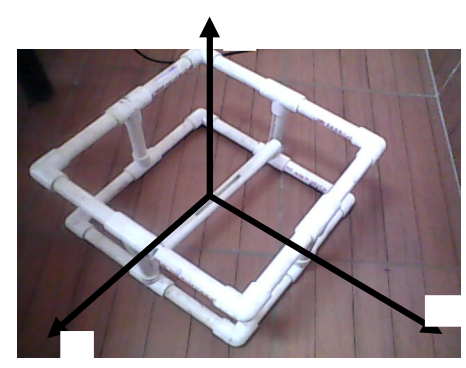

Fig. 1. ROV open frame.

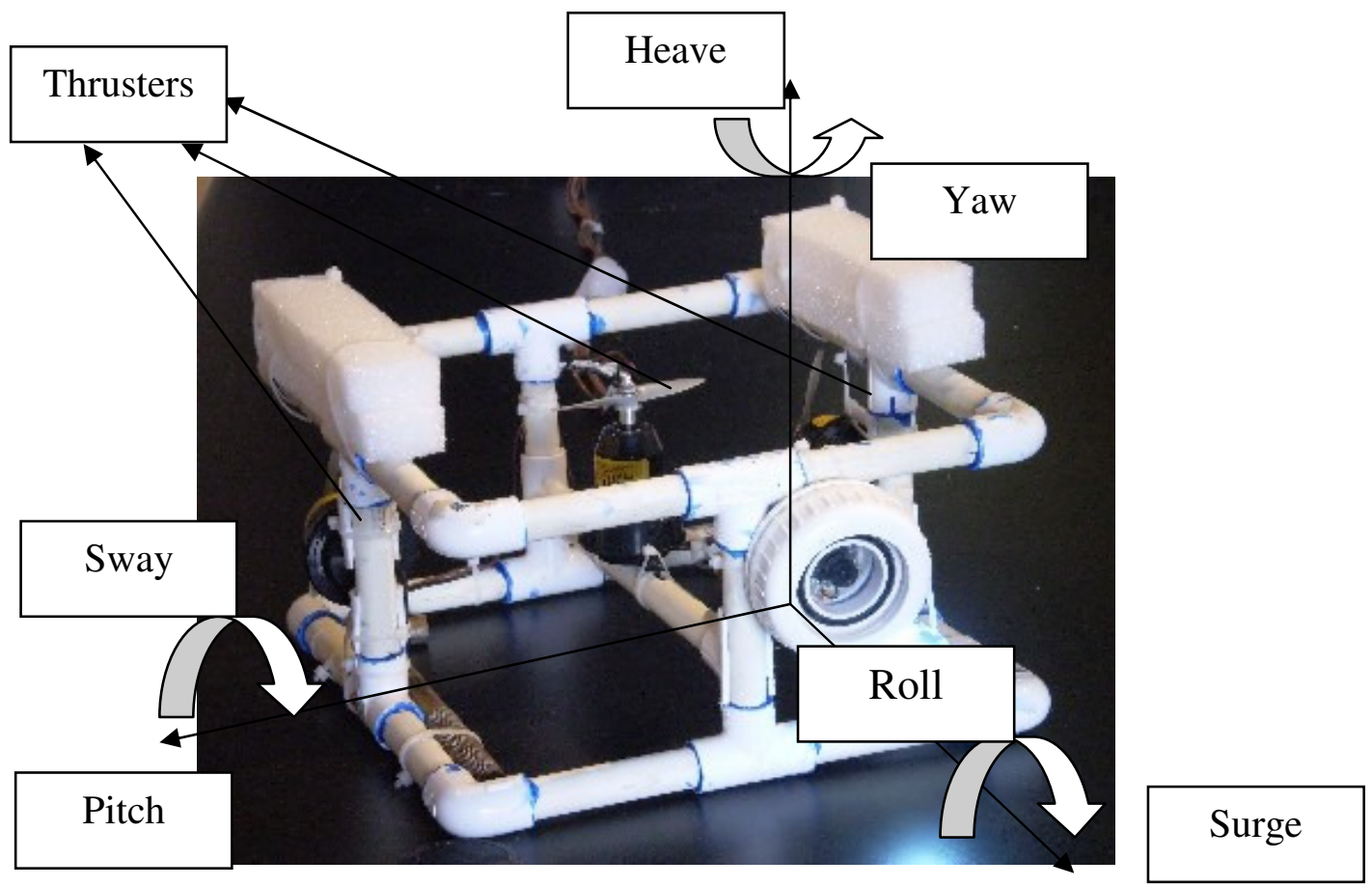

Fig. 2. Thrusters layout.

Fig (2). This configuration support the vehicle with the three degree of freedom motion needed.

\section{Stress Analysis}

\section{Static and dynamic loading}

Remotely operated vehicle usually suffer from two types of loadings, static and dynamic loading. Static loading occurs due to the weight of water column above the structure and obeying the famous rule:

$\mathrm{P}_{\mathrm{s}}=\rho g h$ 
where $\mathrm{P}_{\mathrm{s}}$ is the static pressure, $\rho$ water density, $\mathrm{g}$ gravitational acceleration, and $\mathrm{h}$ is the height of water column above the structure. The height $\mathrm{h}$ is assumed $1000 \mathrm{~m}$ and water density approximately $1000 \mathrm{~kg} / \mathrm{m}^{3}$ then the static pressure equal $\mathrm{P}_{\mathrm{s}}=1000 * 9.81 * 1000=9.81 \mathrm{MPa}$

Dynamic loading occurs due to the speed of the vehicle causing dynamic stress, this stress obeying the Bernoulli equation for steady incompressible fluid,

$\mathrm{P}_{\mathrm{d}}=\frac{1}{2} \rho v^{2}$

where $P_{d}$ is the dynamic pressure, $\rho$ is the water density and $v$ is the ROV velocity.

The normal operating speed of almost all kinds of ROV's is from 0.5 to $1 \mathrm{~m} / \mathrm{s}$. Then the dynamic pressure $P_{d}$ will be:

$P_{d}=1 / 2 * 1000 *(1)^{2}=500 \mathrm{~Pa}$

From previous calculations it is shown that the dynamic pressure, $500 \mathrm{~Pa}$, is minor in comparison with the major static pressure $98.1 \mathrm{MPa}$.

\section{Finite Element Model}

The general purpose finite element package, ABAQUS version 6.8 is used for the analysis of the ROV structure. The ROV frame model made by ABAQUS code considered the frame made of 1 inch PVC tube with overall dimensions of $\left(38^{\star} 38^{*} 18\right.$ $\mathrm{cm}$ ), the frame is subjected to distributed pressure load equivalent to hydrostatic pressure of 1000 meter water column which represents the major source of load on the ROV frame. The dynamic load due to the vehicle velocity from 0.5 to $1 \mathrm{~m} / \mathrm{s}$ is neglected as mentioned in equation (1). The finite element modeling procedures are as follow:

a- In part module, the frame elements are drawn with the same dimensions as real model and the parts are : tube 1" $(25.4 \mathrm{~mm}$ )diameter, $3 \mathrm{~mm}$ thickness and $125 \mathrm{~mm}$ length, elbow 1" diameter, and T connection with 1" diameter, as shown in Fig. 3

b- In property module, the material of the PVC is defined as well as the section, and then is assign to each part of the part module, as shown in Table 1.

c- In the ABAQUS assembly module, the instance of each part is created and the parts are brought together forming the ROV frame, as shown in Fig 4.

d- In step module, the solution is set to be static according to the results needed to be calculated. In the solution the stress and the strain of the frame is calculated.

e- In interaction module, the constrains are assign to the frame nodes and surfaces simulating the real case where some surfaces are glowed with others preventing any slippage, actually this interaction could be done by two ways; the surfaces might be restricted interaction which means that there is no slippage between theses surfaces, or it could be done in instance module by grouping all instances into one part, which is what made here in this model.

$\mathrm{f}$ - In load module, the loads are assign to the frame simulating the forces resulted from the thrusters and also the water pressures (static and dynamic pressure), as shown in Fig. 5 The thrusting force is set to the maximum value 

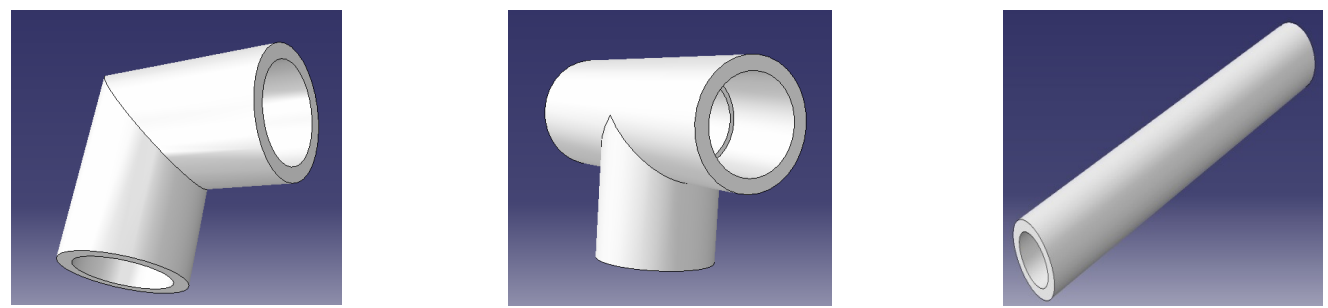

Fig. 3. Parts of ROV frame.

Table 1. PVC properties.

\begin{tabular}{|l|c|}
\hline \multicolumn{1}{|c|}{ Property } & value \\
\hline Specific gravity & 1.4 \\
\hline Tensile strength $\left(\mathrm{N} / \mathrm{mm}^{2}\right)$ & 55 \\
\hline Elongation at break $(\%)$ & 15 \\
\hline Tensile modulus $\left(\mathrm{N} / \mathrm{mm}^{2}\right)$ & 3100 \\
\hline Thermal expansion $\left(10^{-3} / \mathrm{c}^{0}\right)$ & 7 \\
\hline
\end{tabular}

of $(15 \mathrm{~N})$. Rectangular rings placed in the location of the thrusters with side area of $\left(3^{*} 0.5 \mathrm{~cm}\right)$ are loaded by a pressure of $100 \mathrm{KPa}$.

For boundary conditions to simulate the free conditions as the real case study should be, the constrains are set to the corners of the frame to be restricted in one direction only, which make the frame is not allowed to move in any direction and in the same time does not create any concentrated force points in the frame.

g- In mesh module, the parts are seeded then meshed with the suitable meshing element, as shown in Fig. 6.

$\mathrm{h}$ - In job module, the solution process is set to be done to the model assigning the suitable processing setting (dual processors, parallel processing, $600 \mathrm{M}$ Ram cache memory used).

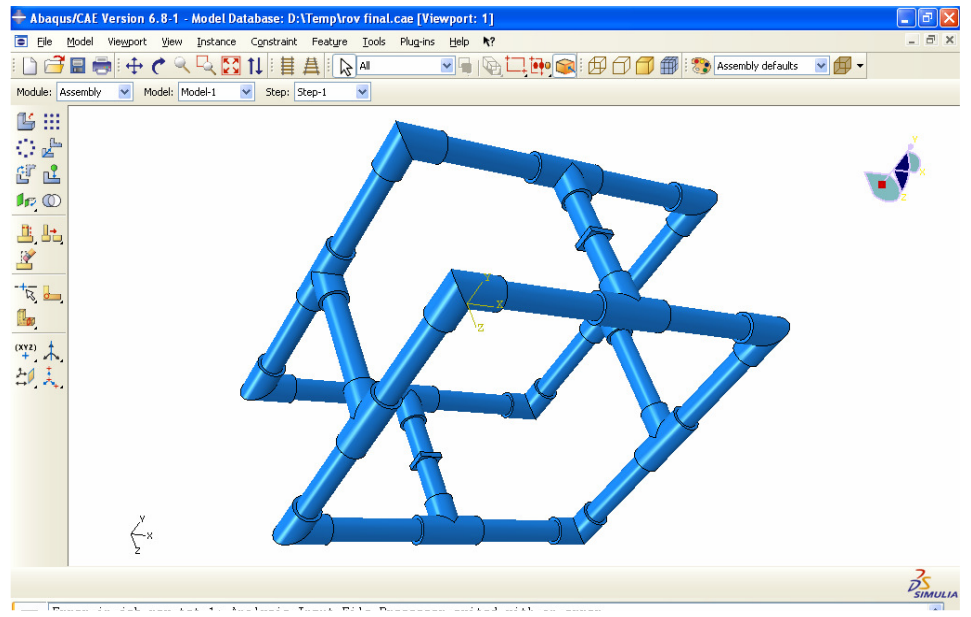

Fig. 4. Assembly of frame components. 


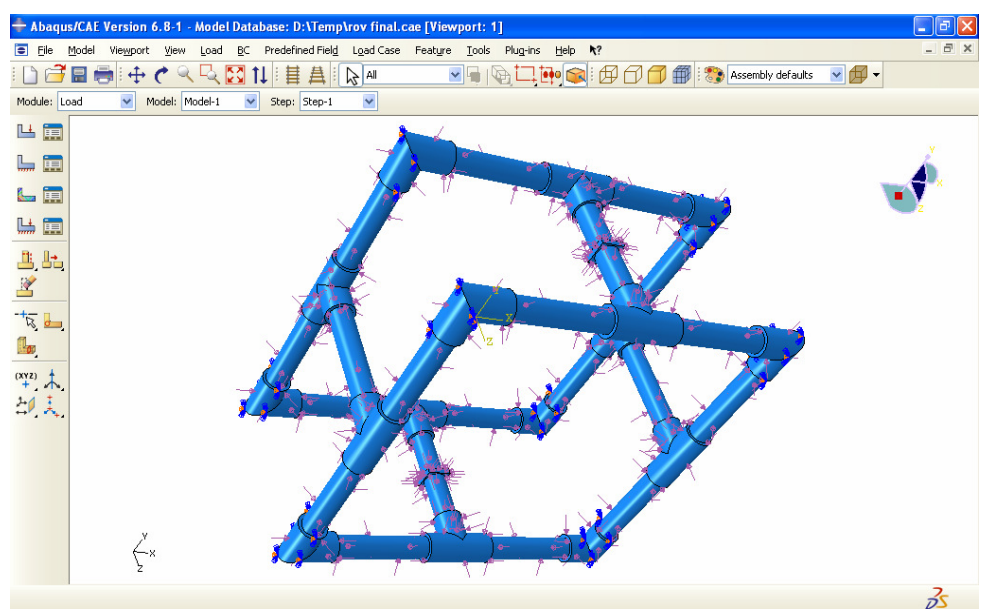

Fig. 5. Loads and Boundary conditions.

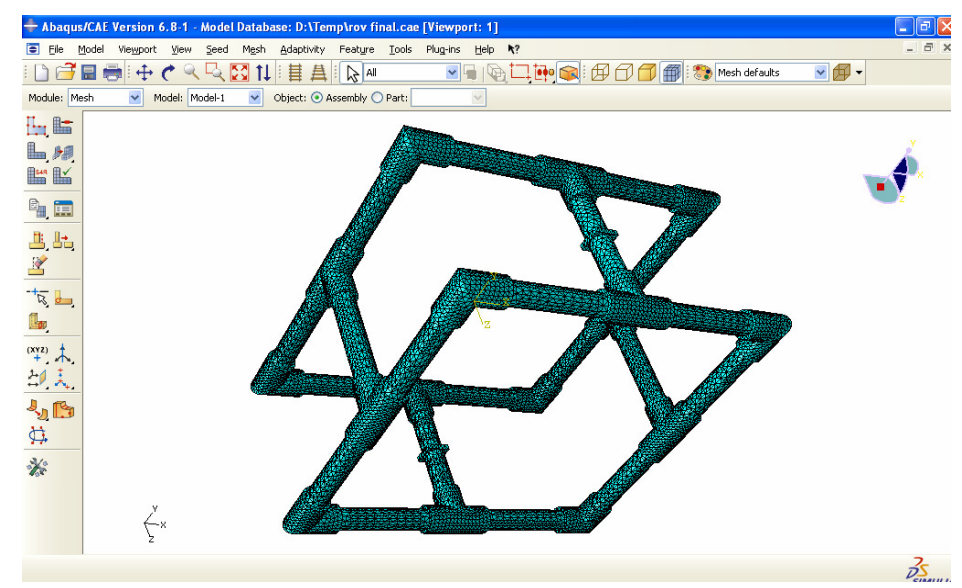

Fig. 6. Mesh module of ROV frame.

\section{Finite Element Model Results}

The stresses on the frame are calculated through running the model and the maximum stress calculated is $29.54 \mathrm{MPa}$ as shown in Fig (7), which is lower than the maximum stress of the PVC material (55 MPa).

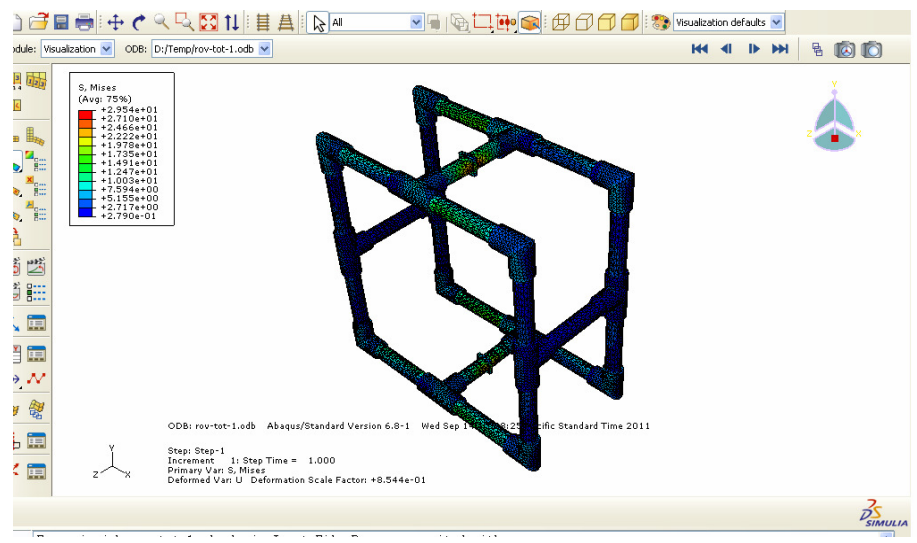

Fig. 7. Stress distribution over ROV frame. 
Maximum strain is (7.097E-3) as shown Fig. (8), which means a small deformation of the frame shape under hydrostatic load.

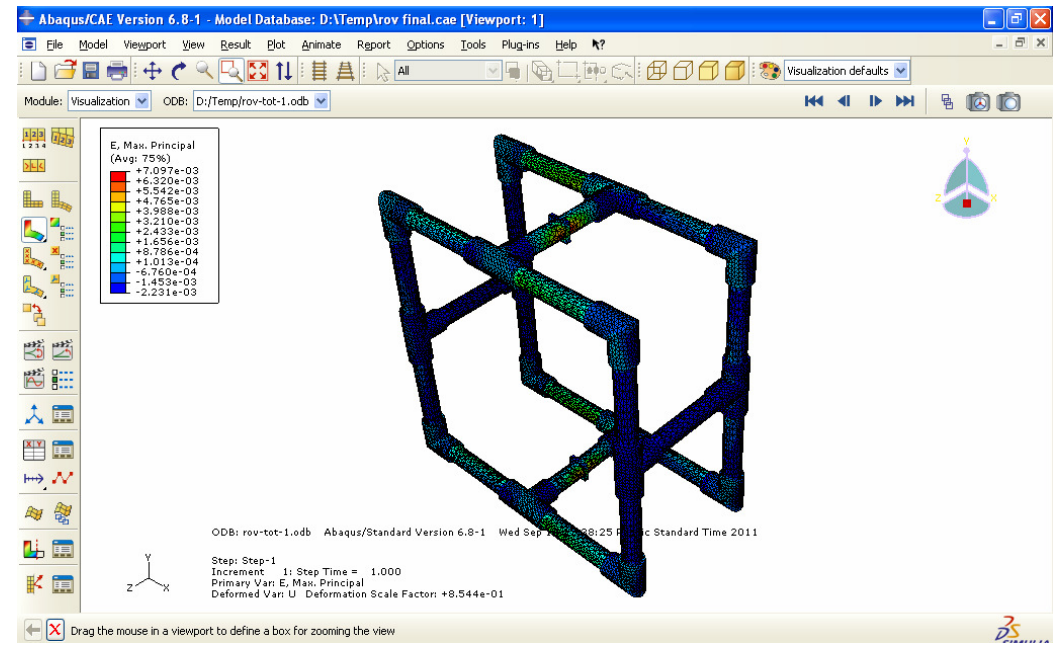

Fig. 8. Strain of vehicle frame under hydrostatic and thruster force.

\section{MATHEMATICAL MODEL}

In order to dynamically analyze the ROV a will established equation of motion should be presented [9], the simplest way is to classify the forces affects the vehicle during motion to four types:

a- Thrusting force vector $[T]$

b- Linear damping force vector $\left[K_{l}\right][\dot{q}]$

c- Quadric damping force vector $\left[K_{q}\right][\dot{q}]^{2}$

d- Added mass inertia force $\left[M_{\text {added }}\right][\ddot{q}]$

$[M][\ddot{q}]+\left[M_{\text {added }}\right][\ddot{q}]+\left[K_{l}\right][\dot{q}]+\left[K_{q}\right]|[\dot{q}]|[\dot{q}]=[T]$

\section{Equivalent Mass Matrix}

For body movies in six degree of freedom (serge, sway, heave, roll, pitch, yaw) a 6x6 mass matrix is presented, it is a diagonal matrix.

$$
[M]=\left[\begin{array}{cccccc}
m & 0 & 0 & 0 & 0 & 0 \\
0 & m & 0 & 0 & 0 & 0 \\
0 & 0 & m & 0 & 0 & 0 \\
0 & 0 & 0 & I_{x} & 0 & 0 \\
0 & 0 & 0 & 0 & I_{y} & 0 \\
0 & 0 & 0 & 0 & 0 & I_{z}
\end{array}\right]
$$

The ROV model shown in Figure (1) is consists of 8 tubes each of length 0.38 meter and $0.0125 \mathrm{~m}$ radius, and 4 tubes of length 0.18 meters and 0.0125 meters radius. The tubes centeroidal mass moments of inertia are calculated and the shift theorem 
is applied. The summation is presented to get the mass moment of inertia of the total structure. The frame is assumed to be filled with water. The frame material density $\rho$ is $1323.3 \mathrm{~kg} / \mathrm{m}^{3}$ and water density of $1000 \mathrm{~kg} / \mathrm{m}^{3}$. For each tube of length $\mathrm{L}$, radius $\mathrm{R}$ and mass $m$, the mass moment of inertia is calculated as shown in Table 2, where $I_{x}, I_{y}$ and $I_{z}$ are local moment of inertia, and $I_{x}^{\prime}, I_{y}^{\prime}$ and $I_{z}^{\prime}$ are total mass moment of inertia with respect to the center of the structure, $m$ is the total mass of the tubes that field with water.

Table 2. Values of the mass and mass moment of inertia for the used structure.

\begin{tabular}{|c|c|c|c|c|c|c|c|c|c|c|}
\hline $\begin{array}{c}\mathrm{L} \\
(\mathrm{cm}) \\
\end{array}$ & M (kg) & $\begin{array}{c}\mathrm{X} \\
(\mathrm{cm}) \\
\end{array}$ & $Y(\mathrm{~cm})$ & $\begin{array}{c}\mathrm{Z} \\
(\mathrm{cm}) \\
\end{array}$ & $\begin{array}{c}\mathrm{IX} \\
\text { kg.m } \\
\end{array}$ & $\begin{array}{c}y \\
\text { kg.m }\end{array}$ & $\begin{array}{c}\mathrm{Iz} \\
\mathrm{kg} \cdot \mathrm{m}^{2} \\
\end{array}$ & $\begin{array}{c}\text { IX' }^{\prime} \\
\text { kg.m }\end{array}$ & $\begin{array}{c}\text { ly' }^{\prime} \\
\text { kg.m }\end{array}$ & $\begin{array}{c}\mathrm{Iz}^{\prime} \\
\mathrm{kg} \cdot \mathrm{m}^{2} \\
\end{array}$ \\
\hline 38 & 0.38 & 0.00 & 7.75 & 17.75 & 0.00 & 45.5 & 45.5 & 141.8 & 164.548 & 68.177 \\
\hline 38 & 0.38 & -17.8 & 7.75 & 0.00 & 45.5 & 45.5 & 0.00 & 68.18 & 164.548 & 141.770 \\
\hline 38 & 0.38 & 0.00 & 7.75 & -17.8 & 0.00 & 45.5 & 45.5 & 141.8 & 164.548 & 68.177 \\
\hline 38 & 0.38 & 17.8 & 7.75 & 0.0 & 45.5 & 45.5 & 0.00 & 68.18 & 164.548 & 141.770 \\
\hline 38 & 0.38 & 0.00 & -7.75 & 17.8 & 0.00 & 45.5 & 45.5 & 141.8 & 164.548 & 68.177 \\
\hline 38 & 0.38 & -17.8 & -7.75 & 0.00 & 45.5 & 45.5 & 0.00 & 68.18 & 164.548 & 141.770 \\
\hline 38 & 0.38 & 0.00 & -7.75 & -17.8 & 0.00 & 45.5 & 45.5 & 141.8 & 164.548 & 68.177 \\
\hline 38 & 0.38 & 17.8 & -7.75 & 0.0 & 45.5 & 45.5 & 0.00 & 68.18 & 164.548 & 141.770 \\
\hline 18 & 0.18 & 0.00 & 0.00 & 17.8 & 4.83 & 0.00 & 4.83 & 61.24 & 56.402 & 4.834 \\
\hline 18 & 0.18 & -17.8 & 0.00 & 0.0 & 4.83 & 0.00 & 4.83 & 4.834 & 56.402 & 61.236 \\
\hline 18 & 0.18 & 0.0 & 0.00 & -17.8 & 4.83 & 0.00 & 4.83 & 61.24 & 56.402 & 4.834 \\
\hline 18 & 0.18 & 17.8 & 0.00 & 0.0 & 4.83 & 0.00 & 4.83 & 4.834 & 56.402 & 61.236 \\
\hline $\begin{array}{l}\text { Total } \\
\text { mass }\end{array}$ & $3.739 \mathrm{~kg}$ & & & & \multicolumn{3}{|c|}{$\begin{array}{l}\text { Mass moment of inertia } \\
\left(\mathrm{kg} \cdot \mathrm{cm}^{2}\right)\end{array}$} & 971.9 & 1541.995 & 971.926 \\
\hline & & & & & \multicolumn{3}{|c|}{$\begin{array}{c}\text { Mass moment of inertia } \\
\left(\mathrm{kg} . \mathrm{m}^{2}\right)\end{array}$} & 0.097 & 0.154 & 0.097 \\
\hline
\end{tabular}

From Table (2) the values of mass and mass moment of inertia are summarized in Table (3).

Table 3. Numerical values of mass and mass moment of inertia.

\begin{tabular}{|c|l|}
\hline Variable & Value \\
\hline $\mathrm{m}$ & $3.739 \mathrm{Kg}$ \\
\hline $\mathrm{I}_{\mathrm{x}^{\prime}}$ & $0.097 \mathrm{Kg} \cdot \mathrm{m}^{2}$ \\
\hline $\mathrm{I}_{\mathrm{y}^{\prime}}$ & $0.154 \mathrm{Kg} \cdot \mathrm{m}^{2}$ \\
\hline $\mathrm{I}_{\mathrm{z}^{\prime}}$ & $0.097 \mathrm{Kg} \cdot \mathrm{m}^{2}$ \\
\hline
\end{tabular}

Substituting the obtained values of mass and mass moment of inertia into the mass matrix form, then the mass matrix will be: 


$$
[M]=\left[\begin{array}{cccccc}
3.739 & 0 & 0 & 0 & 0 & 0 \\
0 & 3.739 & 0 & 0 & 0 & 0 \\
0 & 0 & 3.739 & 0 & 0 & 0 \\
0 & 0 & 0 & 0.097 & 0 & 0 \\
0 & 0 & 0 & 0 & 0.154 & 0 \\
0 & 0 & 0 & 0 & 0 & 0.097
\end{array}\right]
$$

\section{Added Mass}

When a rigid body is moving in a fluid, the additional inertia of the fluid surrounding the body, which is accelerated by the movement of the body, has to be considered. The fluid surrounding the body is accelerated with the body itself, a force is then necessary to achieve this acceleration; the fluid exerts a reaction force which is equal in magnitude and opposite in direction. This reaction force is the added mass contribution.

The added mass is not a quantity of fluid to add to the system such that it has an increased mass as Prof. A.H. Techet [11] said.

If the body is completely submerged in the water, the velocity is low and it has three planes of symmetry as common for underwater vehicles. Gianluca Antonelli [12] divided the added mass matrix into two matrices $M_{A}$ and $C_{A}$ can therefore be considered:

$\mathrm{M}_{\mathrm{A}}=-\operatorname{diag} .\left\{X_{\tilde{u}_{x}}, Y_{\tilde{v}}, Z_{\dot{w}}, K_{\dot{p}}, M_{\dot{q}}, N_{\dot{r}}\right\}$

$\mathrm{C}_{\mathrm{A}}=\left[\begin{array}{cccccc}0 & 0 & 0 & 0 & -Z_{\dot{w}} w & Y_{\dot{v}} v \\ 0 & 0 & 0 & -Z_{\dot{w}} \mathrm{w} & 0 & -X_{\dot{u}} \mathrm{u} \\ 0 & 0 & 0 & -Y_{\dot{v}} v & X_{\dot{u}} \mathrm{u} & 0 \\ 0 & -Z_{\dot{w}} & Y_{v} v & 0 & -N_{r} r & M_{\dot{q}} q \\ -Z_{\dot{w}} w & 0 & -X_{u} & N_{r} r & 0 & -K_{p} p \\ -Y_{\dot{v}} v & X_{\dot{u}} \mathrm{u} & 0 & -M_{\dot{q}} q & K_{p} p & 0\end{array}\right]$

The added mass coefficients can be theoretically derived exploiting the geometry of the rigid body and, eventually, its symmetry, by applying the strip theory. For a cylindrical rigid body of mass $\mathrm{m}$, length $\mathrm{L}$, with circular section of radius $r$, the following added mass coefficients can be derived [12]:

$X_{\dot{u}}=-0.1 \mathrm{~m}$

$Y_{v}=-\pi \rho r^{2} \mathrm{~L}$

$Z_{\bar{w}}=-\pi \rho r^{2} L$

$K_{p}=0$

$M_{\text {审 }}=-1 / 12 \pi \rho r^{2} L^{3}$

$N r^{*}=-1 / 12 \pi \rho r^{2} L^{3}$

Substituting in the above equations leads to the values of the added mass matrix elements as shown in Table (4). 
Table 4. Values of added mass matrix elements.

\begin{tabular}{|l|l|l|}
\hline Element & Value & \\
\hline$X_{\bar{u}}$ & -0.54403 & $\mathrm{Kg}$ \\
\hline$Y_{\bar{v}}$ & -1.564 & $\mathrm{Kg}$ \\
\hline$Z_{\bar{w}}$ & -0.54403 & $\mathrm{Kg}$ \\
\hline$K_{\dot{p}}$ & $-9.93667 \mathrm{E}-06$ & $\mathrm{Kg} \cdot \mathrm{m}^{2}$ \\
\hline$M_{\dot{q}}$ & $-1.7964 \mathrm{E}-05$ & $\mathrm{Kg} \cdot \mathrm{m}^{2}$ \\
\hline $\mathrm{N}_{\mathrm{r} \cdot}$ & $-9.93667 \mathrm{E}-06$ & $\mathrm{Kg} \cdot \mathrm{m}^{2}$ \\
\hline
\end{tabular}

Substituting into equations $(4,5)$

$$
M_{A}=\left[\begin{array}{cccccc}
3.739 & 0 & 0 & 0 & 0.544 w & -1.564 v \\
0 & 3.739 & 0 & -0.544 w & 0 & 0.544 u \\
0 & 0 & 3.739 & 1.09 v & -0.544 u & 0 \\
0 & 0.544 w & -1.564 v & 0.097 & 9.94 E-6 r & -1.79 E-5 q \\
-0.544 w & 0 & 0.544 u & -9.94 E-6 r & 0.154 & 9.94 E-6 p \\
1.564 v & -0.544 u & 0 & 1.79 E-5 q & -9.94 E-6 p & 0.097
\end{array}\right]
$$

Substituting in equation 3.1 the equation of motion of the entire structure will be:

$$
\begin{aligned}
& {\left[\begin{array}{cccccc}
3.739 & 0 & 0 & 0 & 0 & 0 \\
0 & 3.739 & 0 & 0 & 0 & 0 \\
0 & 0 & 3.739 & 0 & 0 & 0 \\
0 & 0 & 0 & 0.097 & 0 & 0 \\
0 & 0 & 0 & 0 & 0.154 & 0 \\
0 & 0 & 0 & 0 & 0 & 0.097
\end{array}\right]\left[\begin{array}{c}
u \\
v \\
\dot{w} \\
\dot{p} \\
q \\
\tilde{z}
\end{array}\right]} \\
& +\left[\begin{array}{cccccc}
0.544 & 0 & 0 & 0 & 0.544 w & -1.564 v \\
0 & 1.564 & 0 & -0.544 w & 0 & 0.544 u \\
0 & 0 & 0.544 & 1.09 v & -0.544 u & 0 \\
0 & 0.544 w & -1.564 v & 9.94 E-6 & 9.94 E-6 r & -1.79 E-5 q \\
-0.544 w & 0 & 0.544 u & -9.94 E-6 r & 1.76 E-5 & 9.94 E-6 p \\
1.564 v & -0.544 u & 0 & 1.79 E-5 q & -9.94 E-6 p & 9.94 E-6
\end{array}\right]\left[\begin{array}{c}
u \\
v \\
w \\
p \\
\dot{q} \\
z^{2}
\end{array}\right] \\
& +\left[K_{Q}\right]\lceil\dot{q} \mid \dot{q} \|]+\left[K_{L}\right][\dot{q}]=[F]
\end{aligned}
$$

For our case study the model is 3 degree of freedom (surge, heave, yaw), or (u,w,q). So the equation of motion will be:

$$
\begin{gathered}
{\left[\begin{array}{ccc}
3.739 & 0 & 0 \\
0 & 3.739 & 0 \\
0 & 0 & 0.154
\end{array}\right]\left[\begin{array}{l}
u \\
w \\
q
\end{array}\right]+\left[\begin{array}{ccc}
0.544 & 0 & 0.544 w \\
0 & 0.544 & 0 \\
-0.544 w & 0 & 1.76 E-5
\end{array}\right]\left[\begin{array}{l}
u \\
w \\
q
\end{array}\right]+\left[K_{Q}\right]\lceil q \mid q \|\rceil} \\
\left.+\left[K_{L}\right] \mid q \dot{q}\right]=[F]
\end{gathered}
$$

Mathematically the added mass matrix components could only be estimated, while the linear and quadric hydrodynamic coefficients are estimated practically or using computational fluid dynamic (CFD) models. 


\section{COMPUTATIONAL FLUID DYNAMIC MODELING}

Estimation of the hydrodynamic coefficients is accomplished by creating a model for the ROV frame, which is subjected to boundary conditions as close as possible to the same conditions of the real case study.

The governing equations are set of equations solved by ANSYS CFX which are the unsteady Navier-Stokes equations in their conservation form. The solution of these equations introduces the solution of the whole problem.

\section{ROV CFD Model}

The ROV CFD model is created using ANSY-CFX 12. The model is composed of the ROV frame, water fluid, inlet, and outlet areas of water. The ROV frame is defined as wall, the water is defined as domain, while the inlet and outlet areas represent the inlet and outlet section of water domain. The inlet boundary condition is applied to inlet section of water domain which is defined by the velocity at inlet. The outlet boundary condition is applied to the outlet section of water domain and the atmospheric pressure is applied to the outlet boundary. The water domain length is set to be ten times the length of ROV.

\section{ROV mesh}

The water (fluid) region, the inlet, outlet, and wall areas are meshed using ANSYSCFX Mesh. The water region is meshed using tetrahedron element. The mesh is 278466 elements as shown in Fig. (9). The inlet and outlet areas are meshed using triangle element. The ROV region is meshed using triangle element. The walls region is meshed using triangle element, the walls is consists of top, bottom, front, and back.

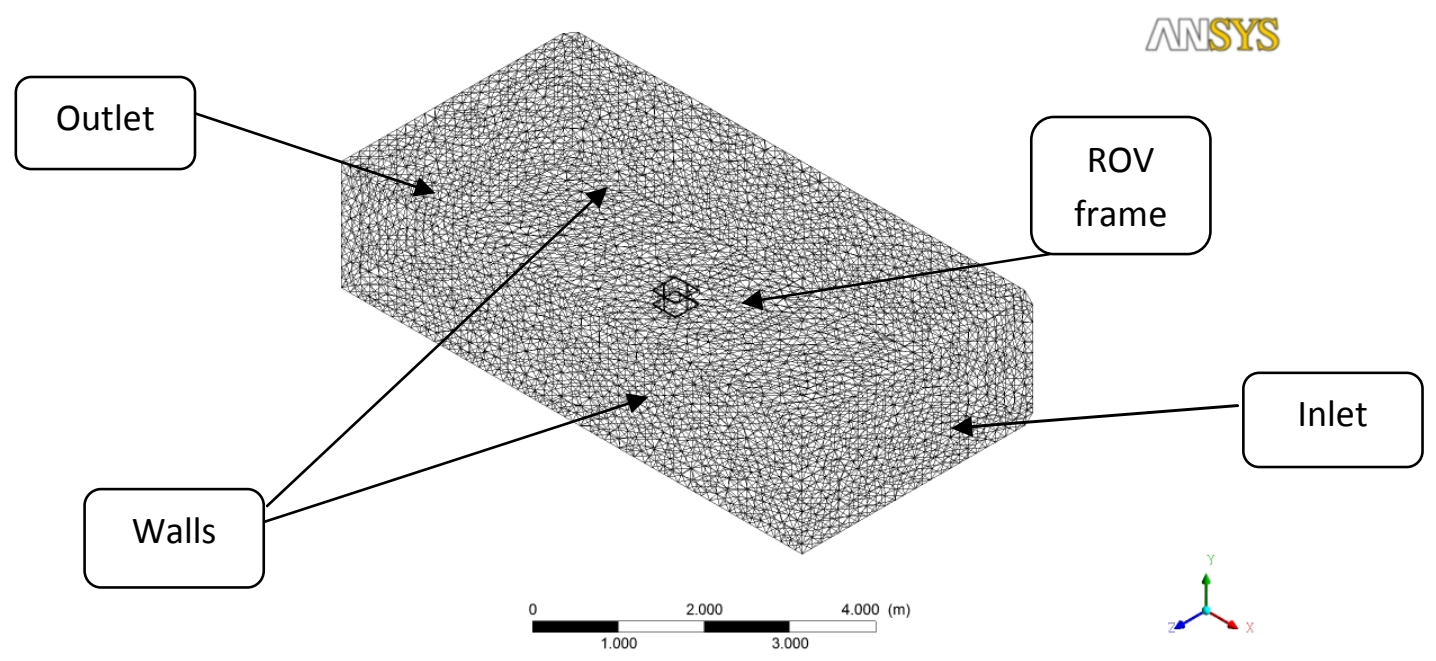

Fig. 9. ROV CFX model mesh.

\section{CFD solution of the ROV in surge direction}

The model is run for the evaluation of the drag force in the ROV region. Water flow is set to inlet from the inlet area, and the outlet is set to atmospheric pressure while the other 4 sides are set as walls. Figure (10) shows this configuration. 


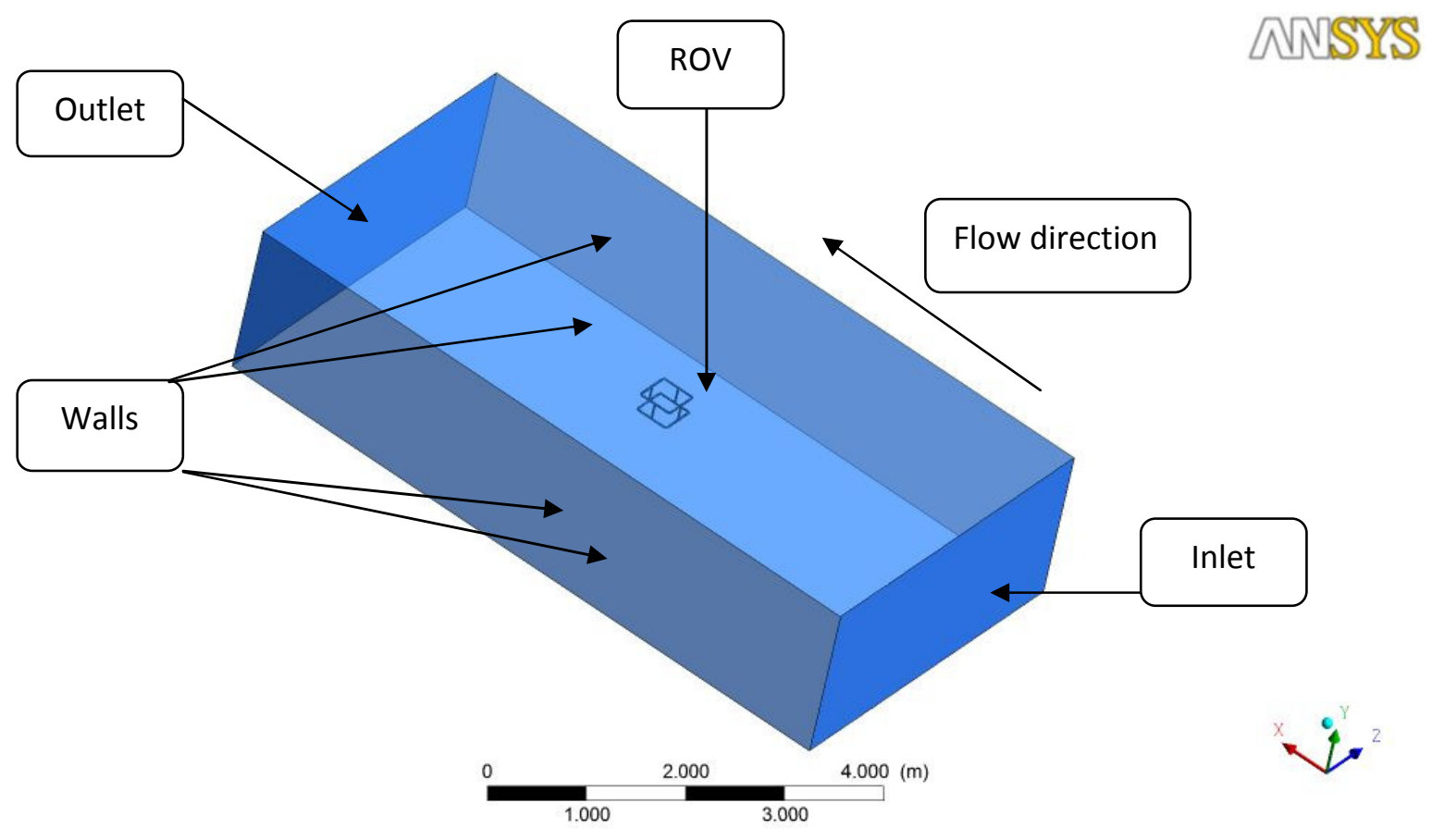

Fig. 10. CFX model for flow in surge direction.

For motion in surge $(x)$ direction the inlet velocity is varied from $0.1 \mathrm{~m} / \mathrm{s}$ to $1 \mathrm{~m} / \mathrm{s}$., while the outlet is set to atmospheric pressure. The value of the drag force in the $x$ direction is obtained as shown in Table 5.

Table 5. Drag force in surge direction.

\begin{tabular}{|c|c|c|c|c|c|c|c|c|c|c|}
\hline $\begin{array}{c}\text { Velocity } \\
\text { (m/s) }\end{array}$ & 0.1 & 0.2 & 0.3 & 0.4 & 0.5 & 0.6 & 0.7 & 0.8 & 0.9 & 1 \\
\hline $\begin{array}{c}\text { Force } \\
(\mathrm{N})\end{array}$ & 6.204 & 12.416 & 18.636 & 24.864 & 31.1 & 37.344 & 43.596 & 49.856 & 56.124 & 62.40 \\
\hline
\end{tabular}

Using the least square method the linear and quadratic damping coefficients are obtained as shown in Table 6.

Table 6. Damping coefficients in surge direction.

\begin{tabular}{|l|l|}
\hline Linear damping coefficient, $\mathrm{N} /(\mathrm{m} / \mathrm{s})$ & 61.89 \\
\hline Quadric damping coefficient, $\mathrm{N} /(\mathrm{m} / \mathrm{s})^{2}$ & 0.398 \\
\hline
\end{tabular}

The same model is used to estimate the force in y direction by changing the inlet and the outlet direction as well as the walls region while the other 4 sides are set as walls. The top is set as inlet velocity, and bottom is set as atmospheric pressure. Fig 10 illustrates the adaptation of the walls and boundaries to estimate the force in heave direction.

The model is run for the evaluation of the drag force in the ROV region heave direction where, the inlet velocity is varied from $0.1 \mathrm{~m} / \mathrm{s}$ to $1 \mathrm{~m} / \mathrm{s}$., the inlet area take 
the variable velocity, while the outlet is set to atmospheric pressure. The values of the force in the y direction are written in Table 7.

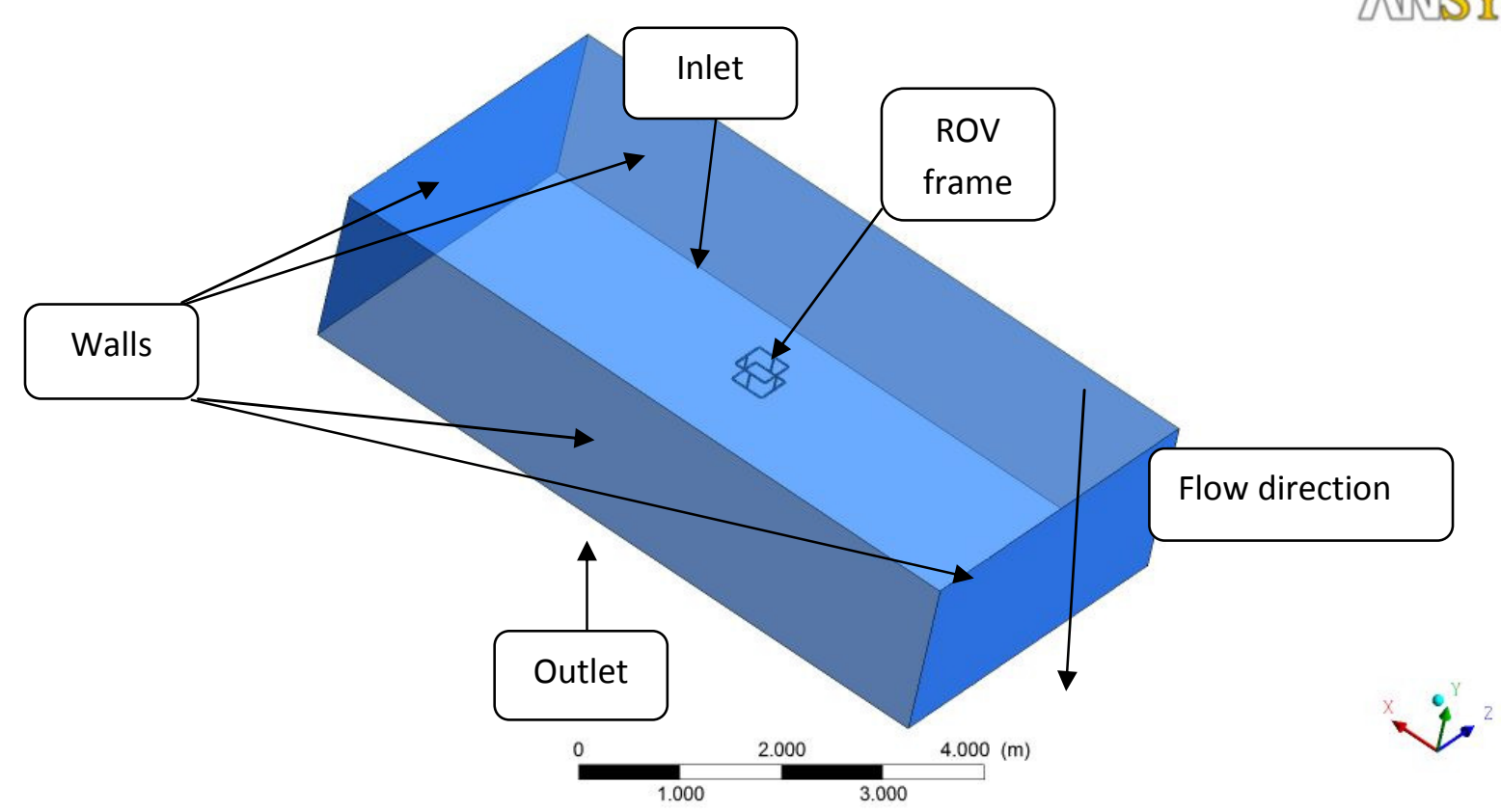

Fig. 11. CFX model for flow in heave direction.

Table 7. Drag Force in heave direction.

\begin{tabular}{|c|c|c|c|c|c|c|c|c|c|c||}
\hline $\begin{array}{c}\text { Velocity } \\
(\mathrm{m} / \mathrm{s})\end{array}$ & 0.1 & 0.2 & 0.3 & 0.4 & 0.5 & 0.6 & 0.7 & 0.8 & 0.9 & 1 \\
\hline $\begin{array}{c}\text { Force } \\
(\mathrm{N})\end{array}$ & 6.204 & 12.416 & 18.636 & 24.864 & 31.1 & 37.344 & 43.596 & 49.856 & 56.124 & 62.40 \\
\hline
\end{tabular}

Using the least square method the damping coefficients is as tabulated in Table 8.

Table 8. Damping coefficients in heave direction.

\begin{tabular}{|l|l|}
\hline \hline Linear damping coefficient, N/(m/s) & 61.59 \\
\hline \hline Quadric damping coefficient, N/(m/s) & 0.415 \\
\hline \hline
\end{tabular}

The results of the linear damping coefficients and quadric damping coefficients for both surge and heave direction are used to establish the equation of motion of the ROV frame in these direction.

The hydrodynamic coefficients in surge and sway directions are the same because of similarity of the frame about $(y)$ axis. 


\section{EXPERIMENTAL WORK}

Hydrodynamic coefficients are essential part of the mathematical modeling of an ROV structure model; these coefficients are estimated by several ways, such as, experimental, analytical and by computational fluid dynamics models. In this part an illustration of experimental setup, procedure and results analysis will be introduced briefly.

\section{Free Decay Pendulum Motion Experiment}

Estimation of hydrodynamic coefficients may obtain by several ways such as tow tank, planer motion mechanism or free decay pendulum motion. The free decay pendulum motion test is used due to its simplicity and low cost in addition to its accepted accuracy. In free decay pendulum motion the model is set to oscillate freely around its equilibrium position under the effect of its own weight and damping force only.

The experimental setup is shown in Fig (12). The model of the ROV is attached to one end of a pendulum which is a slender rod of length $(40 \mathrm{~cm})$. One end is equipped with a fixation to the ROV model and the other end is fixed to ball bearing to support the oscillating motion of the pendulum with minimum friction possible. In the other side of the slender rod an indicator was fixed on the roller bearing, this indicator is a short rod painted in black and marked with a white mark to improve the distinguish of the indicator from its background. Water tank with dimensions $(1 \mathrm{~m} \times 2 \mathrm{~m} \times 1 \mathrm{~m})$ represent the water environment, these dimensions are selected to eliminate the effect of boundary layer formed near the tank walls. The water is fresh water at room temperature with density $\approx 1000 \mathrm{Kg} / \mathrm{m}^{3}$. The ROV frame is fastened to the lower part of the slender rod by plastic straps to prevent any slippage of the frame. A horizontal table is used to support the digital camera parallel to the indicator rod, while the digital camera starts to capture the video of the oscillating motion.

The recorded video is processed using the covariance tracking algorithm [13] to obtain the variation of angle with time digitally. These values is substituted into the next dynamic equations to obtain the hydrodynamic coefficients and added mass.

\section{Dynamic Equation of Free Decay Pendulum}

Consider an object of interest attached at the end of the pendulum and fully submerged in the water. The object moves in a circular path with radius $(r)$ as shown in Fig (13) in the earth-fixed frame, the object is rotating about the pivot point. However, in the body-fixed frame, the object only moves in the surge direction at any instance; the object has only velocity component in surge direction.

The added mass and the damping coefficient are defined in body fixed frame such that,

$F_{H}=m_{a} \ddot{x}+K_{L} \dot{x}+K_{Q}|\dot{x}| \dot{x}$

where $\mathrm{m}_{\mathrm{a}}$ added mass, $\mathrm{K}_{\mathrm{L}}$ and $\mathrm{K}_{\mathrm{Q}}$ are linear and quadric damping coefficient respectively. 


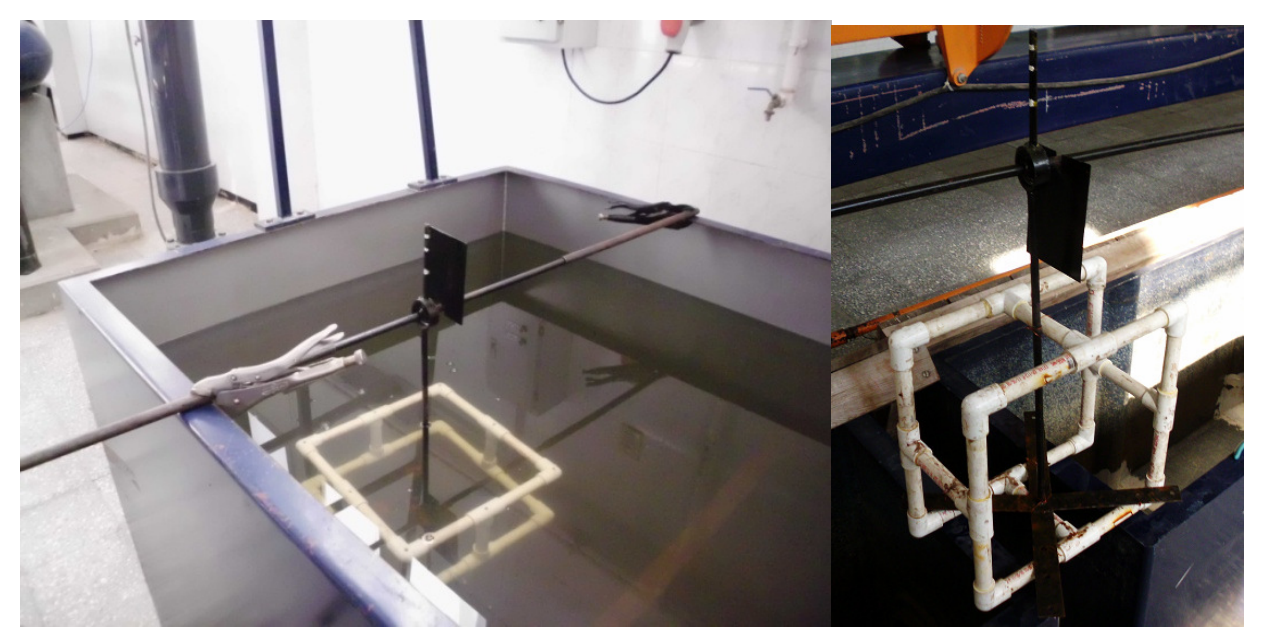

Fig. 12. Experimental set up in surge and heave direction.

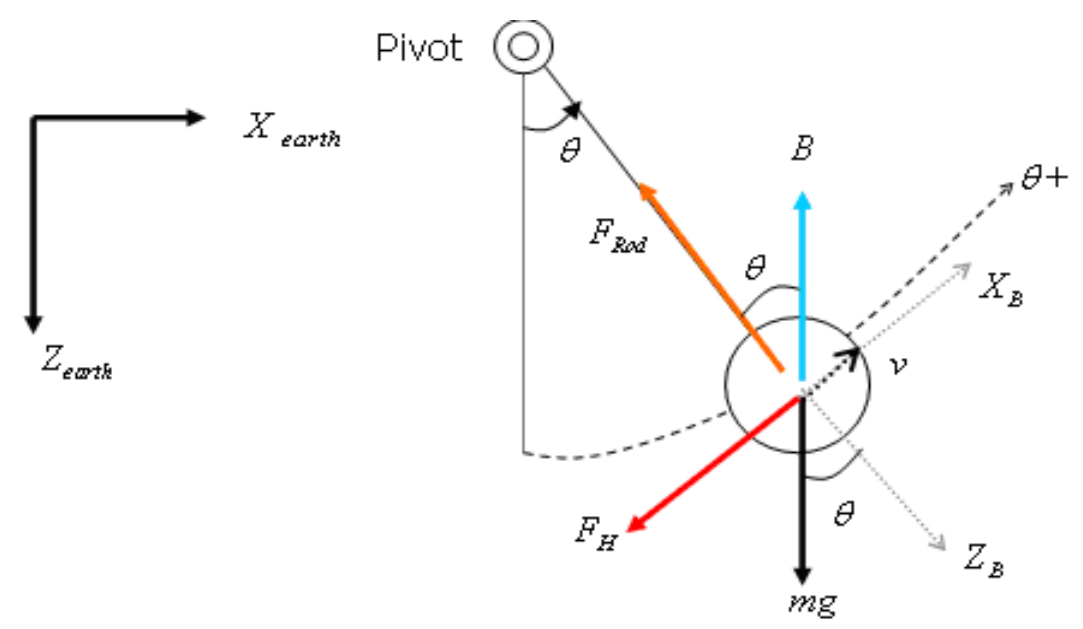

Fig. 13. Free body diagram of the pendulum under hydrodynamics forces.

The equation of motion in the surge direction using Newton's second law of motion:

$\sum F=M x$

$-M g \sin \theta+B \sin \theta-m_{a} \ddot{x}-K_{L} \dot{x}-K_{Q}|\dot{x}| \dot{x}=M \ddot{x}$

Rearranging equation (5.3) gives:

$$
\begin{aligned}
& (B-M g) \sin \theta-K_{\mathrm{L}} \dot{x}-K_{Q}|\dot{x}| \dot{x}=\left(M+m_{a}\right) \dot{x} \\
& \ddot{\mathrm{x}}=\frac{\left(\mathrm{B}-\mathrm{Mg}_{\mathrm{g}}\right)}{\left(\mathrm{M}+\mathrm{m}_{\mathrm{a}}\right)} \sin \theta-\frac{\mathrm{K}_{\mathrm{L}}}{\left(\mathrm{M}+\mathrm{m}_{\mathrm{a}}\right)} \dot{\mathrm{x}}-\frac{\mathrm{K}_{\mathrm{Q}}}{\left(\mathrm{M}+\mathrm{m}_{\mathrm{Q}}\right)}|\dot{\mathrm{x}}| \hat{\mathrm{x}}
\end{aligned}
$$


Equation (5.4) is transferred into rotational motion by substituting $\dot{x}=r \theta$ and $\ddot{x}=r \ddot{\theta}$ then $\ddot{\theta}$ is obtained as:

$\ddot{\theta}=\alpha \cdot \sin \theta-\beta \cdot \theta-\gamma \cdot \theta|\theta|$

where $\alpha=\frac{(\mathrm{B}-\mathrm{Mg})}{\left(\mathrm{M}+\mathrm{m}_{\mathrm{g}}\right)^{\mathrm{r}}}, \beta=\frac{\mathrm{K}_{\mathrm{L}}}{\left(\mathrm{M}+\mathrm{m}_{\mathrm{g}}\right)} \quad$ and $\gamma=\frac{\mathrm{K}_{\mathrm{Q}}, \mathrm{F}}{\left(\mathrm{M}+\mathrm{m}_{\mathrm{g}}\right)}$

Using least square method to obtain the estimated $\alpha, \beta, \gamma$

$$
\underbrace{\left[\begin{array}{c}
\theta_{1} \\
\theta_{2} \\
- \\
-
\end{array}\right]}_{y}=\underbrace{\left[\begin{array}{ccc}
\sin \theta_{1} & \theta_{1} & \theta_{1}\left|\theta_{1}\right| \\
\sin \theta_{2} & \theta_{2} & \theta_{2}\left|\theta_{2}\right| \\
- & - & - \\
- & - & -
\end{array}\right]}_{H(x)} \underbrace{\beta}_{\theta}]_{\gamma}^{\alpha}]+ \text { error }
$$

Subscript $\mathrm{i}=1,2,3 \ldots$ represent the number of samples collected from the experiment result,

$\hat{\theta}_{l S}=\left(H^{T} H\right)^{-1} H^{T} y$

where $\theta_{L S}=\left[\begin{array}{lll}\alpha & \beta & \gamma\end{array}\right]^{T}$

By substituting the numerical values from Table (9) into equation (18), the values of the added mass coefficient, linear damping coefficient and quadric damping coefficient are calculated as shown in Table (10). The free decay experiment is repeated thee times

Table 9. Numerical values of ROV model test.

\begin{tabular}{|l|ll|}
\hline Variable & Value & \\
\hline $\mathrm{M}$ & 3.739 & $\mathrm{Kg}$ \\
\hline $\mathrm{I}_{\mathrm{x}^{\prime}}$ & 0.097 & $\mathrm{Kg} \cdot \mathrm{m}^{2}$ \\
\hline $\mathrm{I}_{\mathrm{y}^{\prime}}$ & 0.154 & $\mathrm{Kg} \cdot \mathrm{m}^{2}$ \\
\hline $\mathrm{I}_{\mathrm{z}^{\prime}}$ & 0.097 & $\mathrm{Kg} \cdot \mathrm{m}^{2}$ \\
\hline $\mathrm{R}$ & 40 & $\mathrm{~cm}$ \\
\hline $\mathrm{B}$ & 2.24 & $\mathrm{~kg}$ \\
\hline
\end{tabular}

where $M$ is total ROV mass, $I_{x^{\prime}}, l_{y^{\prime}}, I_{z^{\prime}}$ are mass moment of inertia, $R$ radius of free decay pendulum and $B$ is buoyancy force.

Repeating the steps for the same frame in heave direction, the hydrodynamic coefficients are obtained as shown in Table (11).

Table 12 show values of linear and quadric damping coefficient as obtained from CFD or experiment. 
Table 10. Values of hydrodynamic coefficients in surge direction.

\begin{tabular}{|c|c|c|c|}
\hline Test & $\begin{array}{c}\text { Added mass } \\
(\mathrm{kg})\end{array}$ & $\begin{array}{c}\text { Linear damping } \\
\text { coff. }(\mathrm{N} /(\mathrm{m} / \mathrm{s}))\end{array}$ & $\begin{array}{c}\text { Quadric damping } \\
\text { coff. }\left(\mathrm{N} /(\mathrm{m} / \mathrm{s})^{2}\right)\end{array}$ \\
\hline 1 & 1.73977 & 59.44488 & 0.348868 \\
\hline 2 & 1.660689 & 62.27559 & 0.282417 \\
\hline 3 & 1.344367 & 48.12204 & 0.365481 \\
\hline Average & 1.581609 & 56.61417 & 0.332256 \\
\hline
\end{tabular}

Table 11. Values of hydrodynamic coefficients in heave direction.

\begin{tabular}{|c|c|c|c|}
\hline Test & $\begin{array}{c}\text { Added mass } \\
(\mathrm{kg})\end{array}$ & $\begin{array}{c}\text { Linear damping } \\
\text { coff. }(\mathrm{N} /(\mathrm{m} / \mathrm{s}))\end{array}$ & $\begin{array}{c}\text { Quadric damping } \\
\text { coff. }\left(\mathrm{N} /(\mathrm{m} / \mathrm{s})^{2}\right)\end{array}$ \\
\hline \hline 1 & 2.45729 & 65.45486 & 0.4162886 \\
\hline 2 & 2.35641 & 68.45864 & 0.39684756 \\
\hline 3 & 2.48923 & 62.89923 & 0.425897 \\
\hline Average & 2.43431 & 65.60424 & 0.413011 \\
\hline
\end{tabular}

Table 12. Comparison between hydrodynamic coefficients in surge and heave direction.

\begin{tabular}{|l|c|c|c|c|}
\hline \multirow{2}{*}{ Test } & \multicolumn{2}{|c|}{ CFD } & \multicolumn{2}{c|}{ Practical } \\
\cline { 2 - 5 } & surge & heave & surge & heave \\
\hline $\begin{array}{l}\text { Linear damping } \\
\text { coff. }(\mathrm{N} /(\mathrm{m} / \mathrm{s}))\end{array}$ & 61.89 & 61.59 & 56.61417 & 65.60424 \\
\hline $\begin{array}{l}\text { Quadric damping } \\
\text { coff. }\left(\mathrm{N} /(\mathrm{m} / \mathrm{s})^{2}\right)\end{array}$ & 0.398 & 0.415 & 0.332256 & 0.413011 \\
\hline
\end{tabular}

\section{DYNAMIC ANALYSES}

To predict the motion behavior of the underwater vehicle under the effect of the thrusting force and the hydrodynamic effect of water, we should build an equation of motion describing this behavior.

Recalling equation of motion 3.1 and write it in surge and heave direction leads to:

$$
\begin{aligned}
& {[M][\ddot{q}]+\left[M_{\text {added }}\right][\ddot{q}]+\left[K_{l}\right][\dot{q}]+\left[K_{q}\right] \mid[\dot{q}] \|[\dot{q}]=[\mathrm{T}]} \\
& m . \ddot{x}+m_{\text {add } x} \cdot \ddot{x}+K_{L x \cdot} \cdot \dot{x}+K_{Q x} \cdot \dot{x}|\dot{x}|=T_{x} \\
& m \cdot \ddot{z}+m_{\text {addz }} \cdot \ddot{z}+K_{L z} \cdot \dot{z}+K_{Q z} \cdot \dot{z}|\dot{z}|=T_{z}
\end{aligned}
$$

Equations $(6.2,6.3)$ are non-homogeneous second order differential equations. The equations are solved numerically using the obtained hydrodynamic coefficients to get 
the relation between velocity, acceleration in surge as will as heave direction with time as shown in Figures (14,15,16,17).

MATLAB software is used to develop a program used for solution of the above equations with thrusting force varying from $5 \mathrm{~N}$ to $30 \mathrm{~N}$.

The figures show that for certain value of thrusting force, as the time increases the velocity also increases until it reaches constant value. It is also noted that as the thrusting force increases the value of surge velocity increases which is logic with the work done by Ming-Chung Fang [4].

The relation between acceleration and time for different thrusting force had been also plotted. It is found that for certain value of thrusting force, as the time increases the acceleration decreases until it reaches constant value of zero. It is also noted that as the thrusting force increases the value of surge acceleration decreases which is logic with the work done by Ming-Chung Fang [4].

\section{DISCUSSION}

Stress analysis of the frame showed that the major factor affects the stress is the hydrostatic load not the dynamic load, especially for normal operating speed of $(0.25$ to $1 \mathrm{~m} / \mathrm{s})$.

The PVC material used in the case study frame with tensile modulus of (3100 MPa) is enough for open frame works beneath $(1000 \mathrm{~m})$ water, but for closed frame vehicle the stresses could be much higher and other materials with higher tensile modulus should be used.

For the case study frame shape used the range of thrusting force needed to move the vehicle within the operating speed range of $(0.2$ to $0.5 \mathrm{~m} / \mathrm{s})$ is $(5 \mathrm{~N}$ to $30 \mathrm{~N})$ in surge direction, while motion in heave direction could use thrusting force less than that value, since the heave speed usually lower than surge speed.

The response of vehicle were estimated by the solution of the vehicle equation of motion these equations have three parameters, linear damping coefficient, quadric damping coefficient and added mass, these coefficients are estimated by different ways.

Damping coefficients are calculated by the ANSYS CFX ${ }^{\circledR}$ and practically with the free decay pendulum motion, while the added mass is calculated mathematically and practically by free decay pendulum motion.

To verify the results accuracy between the solutions of the equation of motion obtained from the substitution of the damping coefficients and the added mass estimated by ANSYS CFX ${ }^{\circledR}$ and practical test made by free decay pendulum motion and substituting in equations (6) and (8). The coefficients estimated with the CFX model and mathematically could be considered theoretical where it depended on mathematical equations, while the coefficients estimated by experimental test are considered practical. 
ANSYS CFX ${ }^{\circledR}$ give an estimation of the damping coefficients (linear and quadric), while the added mass is calculated mathematically using equation (6) in surge direction, and (8) in heave direction. These values are used to substitute into the equation of motion, and the relation between velocity and time in surge direction were plotted and compared with the solution of the equation of motion obtained from the practical estimation of the damping coefficients and added mass in surge direction as shown in Fig. (18).

The acceleration also is plotted for both theoretical and practical coefficients estimations as shown in Fig. (19). Furthermore Figures $(20,21)$ represent the same comparison for velocity and acceleration in heave direction, which are estimated theoretically and practically.

It was clear from Fig's. $(19,21)$ that the initial acceleration estimated theoretically was greater than the estimated practically, that is because the main factor effected the initial acceleration is the added mass, and theoretically the added mass was calculated as if the frame was composed of tubes only and did not include tee connections and elbows, while the practical estimation considered the whole structure. In both estimations the acceleration decays to zero with time where the drag force increases with the vehicle's velocity increases until it equals the thrusting force. Figures $(18,19,20$ and 21) shows that the vehicles response estimated practically and theoretically were quit similar verifying that the methods used quit accurate.

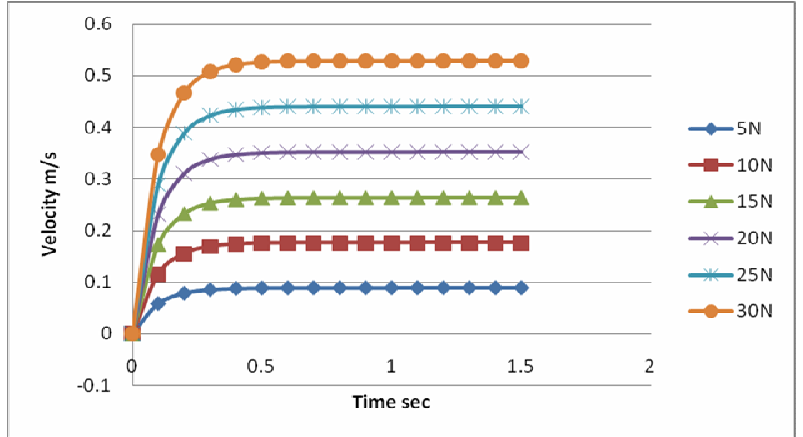

Fig. 14. Variation of velocity with time in surge direction at different thrusting force.

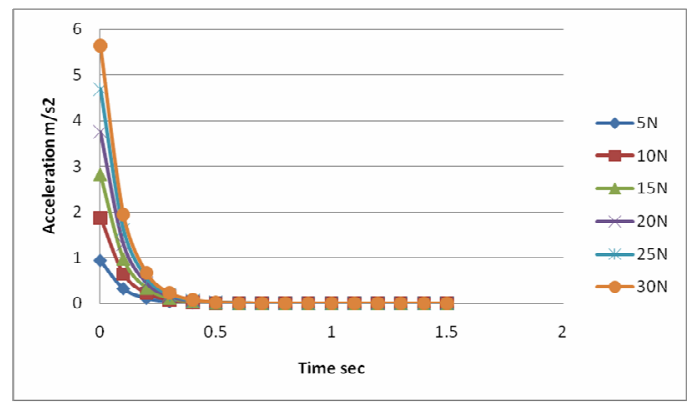

Fig. 15. Acceleration $\left(\mathrm{m} / \mathrm{s}^{2}\right)$ Vs. Time $(\mathrm{sec})$ for different thrusting force (surge).

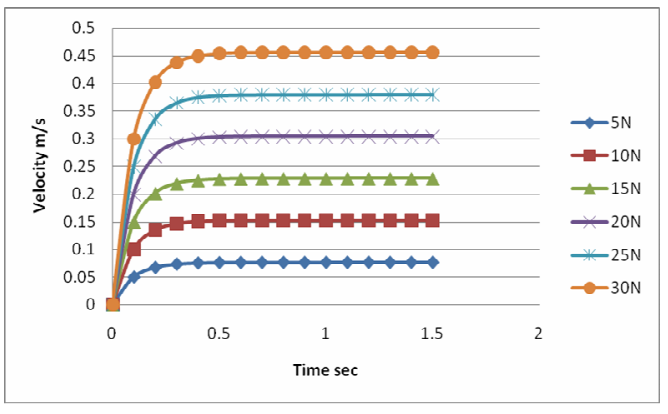

Fig.16. Velocity (m/s) Vs. Time (sec) for different thrusting force (heave).

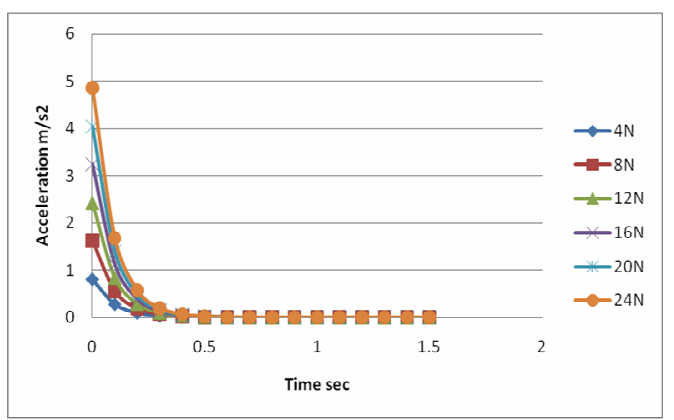

Fig. 17. Acceleration $\left(\mathrm{m} / \mathrm{s}^{2}\right) \mathrm{Vs}$. Time (sec) for different thrusting force (heave). 


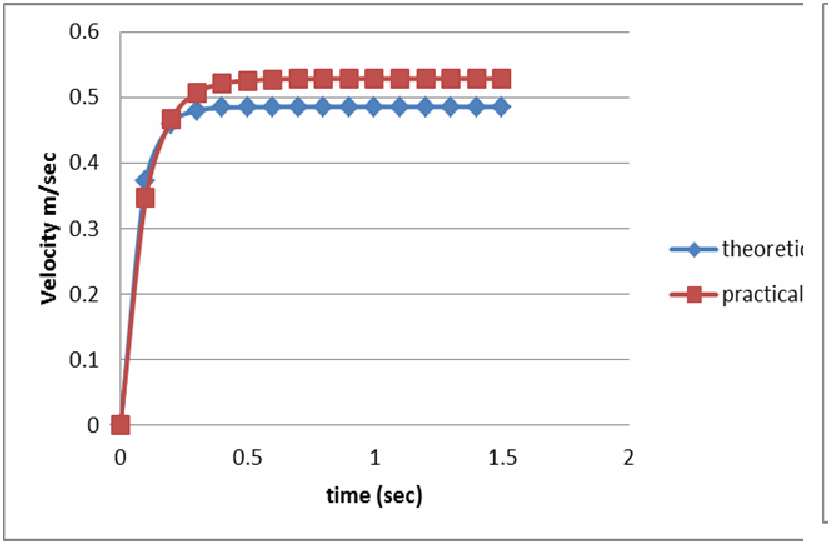

Fig. 18. Vehicle's velocity Vs time theoretically and practically in surge direction.

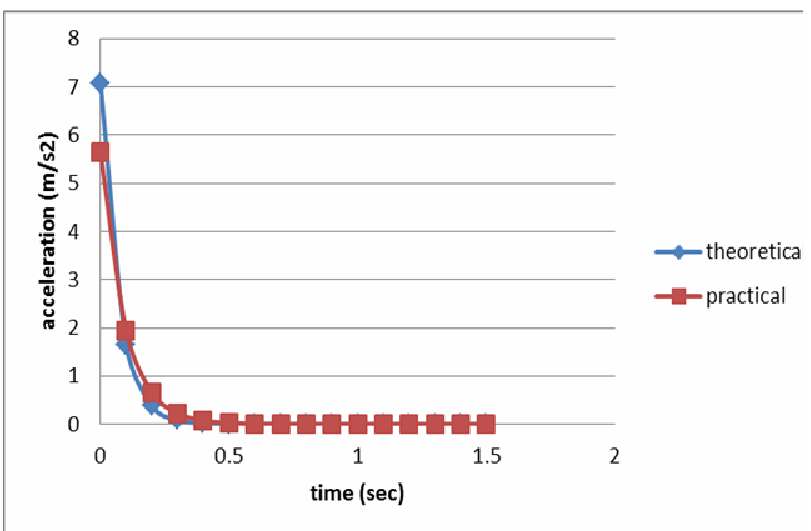

Fig. 19. Vehicle's acceleration Vs time theoretically and practically in surge direction.

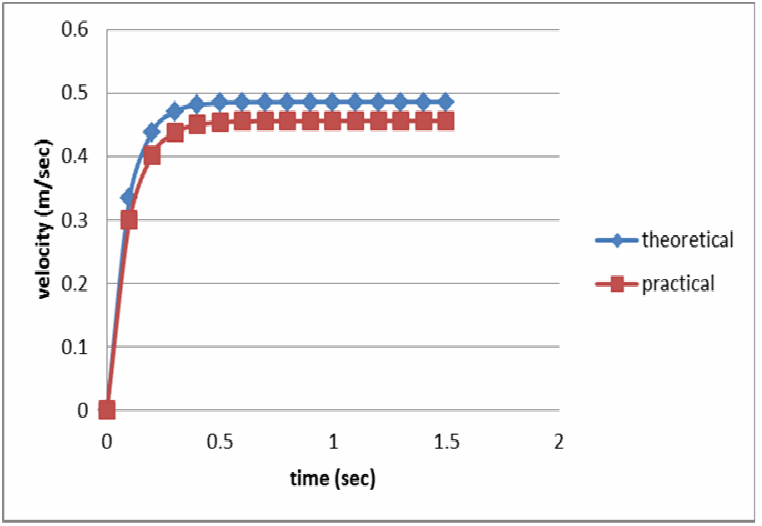

Fig. 20. Vehicle's velocity Vs time theoretically and practically in heave direction.

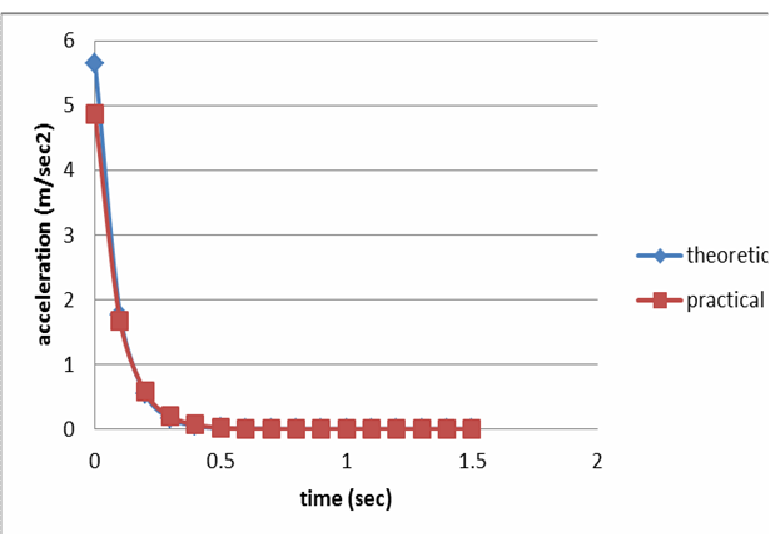

Fig. 21. Vehicle's acceleration Vs time theoretically and practically in heave direction.

\section{CONCLUSIONS}

The conclusion of the proposed research is summarized in the following points:

a. For open frame underwater vehicle PVC material is suitable, but for closed frame underwater vehicle other materials should be used.

b. Dynamic stress for high speed vehicles should be estimated, while for low speed vehicles it can be neglected.

c. For more accurate modeling, the ambient flow velocity effect on thrusting force value should be calculated, since the thrusting force is constant, but it varies with the vehicle speed.

d. Free decay pendulum motion test is suitable for simple modeling of two direction motion vehicle, but for full simulation of six degree of freedom vehicle a planner motion mechanism is preferred.

e. Good agreement is achieved between the hydrodynamic coefficients obtained using practical and CFD models. 


\section{REFERENCES}

[1] F.R. Driscolla, R.G. Lueckb, M. Nahon, "Development and validation of a lumped-mass dynamics model of a deep-sea ROV system", J of Applied Ocean Research 22, pp 169-182, 2000.

[2] B. Buckham, M. Nahon, M. Seto, X. Zhao, C. Lambert, "Dynamics and control of a towed underwater vehicle system, part I: model development", J of Ocean Engineering 30, pp 453-470, 2003.

[3] Jason Evans, Meyer Nahon "Dynamics modeling and performance evaluation of an autonomous underwater vehicle", $\mathrm{J}$ of Ocean Engineering 31, pp 18351858, 2004.

[4] Ming-Chung Fang, Chang-Shang Hou, Jhih-Hong Luo "On the motions of the underwater remotely operated vehicle with the umbilical cable effect", J of Ocean Engineering 34, pp1275-1289, 2007.

[5] ZHU Ke-qiang, ZHU Hai-yang, ZHANG Yu-song, GAO Jie, "A multi-body space-coupled motion simulation for a deep-sea tethered remotely operated vehicle", Journal of Hydrodynamic, 20(2), pp 210-215, 2008.

[6] Jinhyun Kim, Wan Kyun Chung, "Accurate and practical thruster modeling for underwater vehicles", J of Ocean Engineering 33, pp 566-586, 2006.

[7] François Axisa and Jose Antunes, "Modeling of Mechanical Systems: J of Fluid Structure Interaction", Volume 3, pp 1-4.

[8] Peter Stevenson, Derek graham, "Advanced Materials and Their Influence on The Structural Design of AUV's, "Technology and Applications of Autonomous Underwater Vehicle", pp 77-91.

[9] Andrew Ross, Thor I. Fossen, Tor Arne Johansen, "Identification of Underwater Vehicle Hydrodynamic Coefficients Using Free Decay Tests", 2004.

[10] Eng YH, Lau WS, Low E., Seet GGL and CS Chin, "Estimation of the Hydrodynamics Coefficients of an ROV using Free Decay Pendulum Motion", Engineering Letters, 16:3, EL_16_3_09, 2008.

[11] Prof. A.H. Techet, "Hydrodynamics Readings", A. Techet , 2005.

[12] Gianluca Antonelli, "Underwater Robots Motion and Force Control of VehicleManipulator Systems”, Second edition, (P26-29), 2006.

F. Porikli and O. Tuzel. Multi-kernel object tracking. In Proceedings of IEEE Int'l. Conference on Multimedia and Expo, Amsterdam, Netherlands, 2005. 